\title{
The Physical and Psychological Well-Being of Immigrant Children
}

\author{
Krista M. Perreira and India J. Ornelas
}

\section{Summary}

Poor childhood health contributes to lower socioeconomic status in adulthood. Subsequently, low socioeconomic status among parents contributes to poor childhood health outcomes in the next generation. This cycle can be particularly pernicious for vulnerable and low-income minority populations, including many children of immigrants. And because of the rapid growth in the numbers of immigrant children, this cycle also has implications for the nation as a whole. By promoting the physical well-being and emotional health of children of immigrants, health professionals and policy makers can ultimately improve the long-term economic prospects of the next generation.

Despite their poorer socioeconomic circumstances and the stress associated with migration and acculturation, foreign-born children who immigrate to the United States typically have lower mortality and morbidity risks than U.S. children born to immigrant parents. Over time, however, and across generations, the health advantage of immigrant children fades. For example, researchers have found that the share of adolescents who are overweight or obese, a key indicator of physical health, is lowest for foreign-born youth, but these shares grow larger for each generation and increase rapidly as youth transition into adulthood.

Access to health care substantially influences the physical and emotional health status of immigrant children. Less likely to have health insurance and regular access to medical care services than nonimmigrants, immigrant parents delay or forgo needed care for their children. When children finally receive care, it is often in the emergency room after an urgent condition has developed.

To better promote the health of children of immigrants, health researchers and reformers must improve their understanding of the unique experiences of immigrant children; increase access to medical care and the capacity of providers to work with multilingual and multicultural populations; and continue to improve the availability and affordability of health insurance for all Americans.

www.futureofchildren.org

Krista M. Perreira is an associate professor in the Department of Public Policy and a faculty fellow at the Carolina Population Center at the University of North Carolina-Chapel Hill. India J. Ornelas is a postdoctoral fellow in the Biobehavioral Cancer Prevention Training Program at the Fred Hutchinson Cancer Research Center and the University of Washington, both in Seattle. 


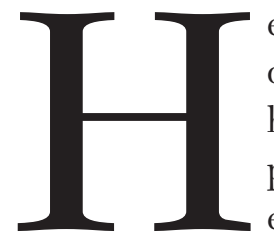

ealth status is a vital aspect of human capital. Unhealthy workers are less productive, more costly for employers, and earn less

over their lifetimes. A growing literature links adult ailments to childhood experiences. For example, childhood asthma and obesity rates are associated with a myriad of chronic illnesses in adulthood (such as diabetes, hypertension, and coronary disease). For the children of immigrants, poverty, the stresses of migration, and the challenges of acculturation can substantially increase their risk for the development of physical and mental health problems. This article documents the evidence about differences in the health status of immigrant youth, including systematic variation in health-compromising behavior and access to health services. It concludes with a discussion of policy implications and strategies to reverse the troubling trends.

Numerous studies document the human capital cost of poor health in adulthood. Obesity, psychiatric disorders, and substance use, for example, affect large numbers of Americans and have all been shown to reduce adult employment and earnings significantly. ${ }^{1}$ Largely because of technical challenges and data limitations, fewer studies have examined the human capital costs of poor health in childhood. Nevertheless, evidence that poor childhood health negatively influences adult education, employment, and socioeconomic status has begun to accumulate.

Early research into the human capital costs of poor childhood health evaluated the educational consequences of teenage childbearing and substance use, especially alcohol and illicit drug use. Results were mixed, with some analysts finding significant reductions in educational attainment-lower rates of high school graduation, college graduation, and years of schooling-related to illicit drug use. Other studies found small or insignificant reductions in educational attainment related to alcohol use or teenage childbearing. ${ }^{2}$

More recent studies have examined the consequences of childhood illnesses, nutrition, physical activity, excessive weight, and mental health for educational attainment, measured by grade completion and graduation, and for achievement, measured by grades and test scores. These analyses demonstrate that the negative consequences of poor childhood health are apparent as early as kindergarten and continue into adulthood. ${ }^{3}$ Childhood asthma and other illnesses result in frequent emergency room visits, hospitalizations, and school absenteeism, and consequently lower math and reading achievement. ${ }^{4}$ Childhood mental health or behavioral problems such as depression and hyperactivity negatively influence performance on standardized math and reading scores in elementary school. Mental health and behavioral problems also increase the likelihood of dropping out of high school and not attending college. ${ }^{5}$ In contrast, good nutrition and regular physical activity in elementary school can improve school attendance, engagement in school, and academic performance. ${ }^{6}$

Even when studies find that child health or health behaviors have only a small influence on educational outcomes, the economic costs of poor child health and health behaviors can be high. The negative effects of poor health in childhood can persist and accumulate over time. Therefore, adults with poor childhood physical or mental health or unhealthy behaviors can experience lower rates of labor force participation, employment, and, ultimately, earnings. ${ }^{7}$ Subsequently, the low socioeconomic status 
of these adults contributes to poor childhood health outcomes among their children. As a result, poor childhood health perpetuates socioeconomic inequalities across family generations. ${ }^{8}$ This cycle can be particularly pernicious for low-income minority populations such as the children of disadvantaged immigrants and, because of the rapid growth in the numbers of immigrant children, for the nation as a whole.

\section{The Role of Migration in Shaping Children's Health}

Migration and the subsequent acculturation experiences of children growing up in immigrant families increase the potential vulnerability of these children and can profoundly shape their health. The concept of acculturation describes the process of cultural change and adaptation that occurs when two or more ethnic groups come into contact with one another. The concept of enculturation describes the opposite- the process of retaining distinct cultural identities, beliefs, and norms of behavior that distinguish one ethnic group from another. Both influence child development and health outcomes.

Cultural-ecological theories argue that the resources in children's families, schools, and neighborhoods influence their lifestyles, daily experiences, and developmental outcomes. ${ }^{9}$

Because migration exposes children to unique developmental demands and stressors associated with acculturation, it reshapes their normative development. To adapt, immigrant children and their families choose different combinations of acculturation and enculturation strategies.

A modified version of Carlos Sluzki's framework for the stages of migration provides a template for understanding sources of stress throughout the migration process and the health consequences of these stressors. ${ }^{10}$ In the pre-migration stage, children's parents decide to leave their home country. These decisions typically reflect economic hardships in their home countries, political unrest and persecution, or the desire to reunify with family already living in the United States. This background sets the stage for children's subsequent migration and acculturation experiences and their influence on children's health. The migration stage captures the mobility process of migrating, including whether the children walk, drive, fly, or come by ship; whether they travel with a trusted family member or friend or are smuggled into the country; and whether they experience hardships during travel such as detainment in a refugee camp, assault, or hunger. The post-migration stage pertains to the settlement experiences of children; the process of navigating life in a new country; and the realization of changes in family economic situations, dynamics, and social roles. Premigration and migration influences are critical to children of immigrants, whereas postmigration influences are critical to second and later immigrant generations as well.

In this article the term "first-generation immigrant children" refers to foreign-born children with foreign-born parents. The term "second-generation immigrants" refers to U.S.-born children with at least one foreign-born parent. The term "children of immigrants" refers to both first- and secondgeneration immigrants as a whole. U.S.-born children with U.S.-born parents are considered "native," or third generation and higher.

\section{Pre-Migration Experience and Health}

Poverty, family separation, and political violence can substantially influence the health of children who immigrate to the United States. Yet few studies of immigrant 
health examine these pre-migration influences. For example, in less developed countries, the prevalence of excessive weight (overweight and obesity) tends to increase with socioeconomic status-higher incomes are associated with the adoption of highcalorie diets and an increase in sedentary activities such as watching television. Thus, low-income children who migrate from these countries are more likely to be at risk of malnutrition and stunting than of being overweight. To demonstrate the importance of pre-migration poverty, Jennifer Van Hook and Kelly Balistreri examined differences in body mass index (BMI) by levels of economic development in children's country of origin. ${ }^{11}$ They found that the BMIs and BMI growth rates were lower for low-income children of immigrants (aged five to eight) from less developed countries than for children of immigrants from high socioeconomic backgrounds in the same countries or for children of immigrants from more developed countries.

In another study of 385 young children of immigrants (aged nine to fourteen), Carola Suárez-Orozco and others found that as many as 85 percent of these children had been separated from one or both parents for a few months to a few years. ${ }^{12}$ Central Americans and Haitians experienced the highest family separation rates (96 percent), whereas Chinese children had the lowest rates (37 percent). These family separations placed children and their mothers at risk for depressive symptoms. A study focusing on children in Mexico whose primary caregivers had migrated found that these children were more likely than children in nonmigrant households to have frequent illnesses (10 percent versus 3 percent), chronic illnesses ( 7 percent versus 3 percent), emotional problems (10 percent versus 4 percent), and behavioral problems ( 17 percent versus 10 percent)..$^{13}$ Thus, as Nancy Landale, Kevin Thomas, and Jennifer Van Hook also highlight in the article in this issue on living arrangements, separation from a parent or primary caregiver who has migrated is associated with poor emotional and physical health among the children left behind.

Although a relatively small population (21,713 children under age eighteen in 2008) the children of refugees can experience additional hardships. ${ }^{14}$ Studies focusing on refugee populations and forced migration find that 80-90 percent of refugee children have experienced extreme hardships such as witnessing murders or mass killings, enduring forced labor, or going without sufficient food for long periods of time. ${ }^{15}$ Others survive combat experiences as child soldiers, life in refugee camps, and, for children who migrate to the United States to seek asylum and who do not have a guardian, long waits in detention centers or juvenile jails. Studies of adolescent Cuban and Cambodian refugees have found a high prevalence (50-60 percent) of both post-traumatic stress disorder and depression for up to two years after they arrive in the United States. In addition to exposures that threaten their emotional health, refugee children often have endured diarrheal disease, malnutrition, fractures, and other acute physical health problems, and experience chronic health problems after resettlement. Latent tuberculosis infections, fungal and parasitic infections, and lead poisoning are just a few of the physical health ailments common to refugee children.

These risk factors (poverty, family separation, and political violence), together with low rates of health insurance coverage and health care use, should lead to poorer health among foreign-born children than among U.S.-born 
Separation from a parent or primary caregiver who has migrated is associated with poor emotional and physical health among the children left behind. Nevertheless, researchers consistently find an immigrant health advantage across a variety of medical outcomes.

children. Nevertheless, researchers consistently find an immigrant health advantage across a variety of medical outcomes. Three causes partially explain this paradox. First, foreign-born immigrant children engage in a variety of more positive health behaviors than their U.S.-born peers. They smoke less, drink less, and eat more nutritional and fewer snack foods. Second, foreign-born children tend to live in two-parent and multigenerational households with high levels of family support and other social support that can mitigate stress, especially during the initial settlement period. ${ }^{16}$ Third, children who immigrate may be a selectively healthy group. Parents whose children have physical or emotional health problems could be less likely to immigrate or bring their children to the United States or more likely to send ill children back to their home countries. Although skeptics abound, research provides weak support for the selective migration of healthy adults. ${ }^{17}$ But to our knowledge, no studies have examined the selective migration of children. In addition, most studies of health selection have focused on Mexican populations, and selection effects may vary by country of origin or even by regions within a country.

\section{Migration Experience and Health}

Few quantitative survey data exist about the nature of youths' migration experiences, but ethnographers and journalists have written extensively about these experiences. For documented children, migration to the United States may involve a relatively short plane trip and little trauma. For undocumented children, the migration journey can take months and involve severe physical and emotional hardship. Enrique's Journey, the true story of a sixteen-year-old boy's perilous trip from Honduras in search of his mother, typifies the physical and emotional trauma that at least some first-generation children experience on their way to the United States. ${ }^{18}$

In one mixed-methods study, 59 percent of Latino adolescents, aged twelve to eighteen, who had recently immigrated to North Carolina told researchers that the migration experience was somewhat to very stressful. ${ }^{19}$ Although only 8 percent of these youth traveled alone or with a smuggler, 46 percent of the adolescents surveyed were concerned for their safety during their travels, 4 percent were robbed, 1 percent were physically attacked, 11 percent were accidentally injured, and 16 percent fell sick. Many of these migrants arrived in the United States injured, emotionally distressed, and in need of either physical or mental health services.

\section{Post-Migration Experiences,}

Acculturation, and Health

Most of the research on the well-being of first-generation children focuses on their post-migration experiences. These experiences include a large number of acculturation stressors such as learning a new lan- 
guage, coping with changes in family roles and responsibilities, protecting one's legal status or the legal status of family members, and encountering racism or discrimination. Although these stressors are common, their influence on a child's health can vary tremendously depending on the length of time the child has lived in the United States, the broader social context of settlement, and the child's age or developmental stage at migration.

Studies measuring the influences of these post-migration stressors on the health of Hispanic children typically use stress inventories such as the Hispanic Stress Index and the Societal, Attitudinal, Familial, and Environmental Acculturative Stress Scale. Nearly all of these studies focus on the strong negative relationship between stressors and children's emotional well-being. Researchers have not yet evaluated relationships between acculturation stressors and physical health outcomes; acculturation stress inventories have not yet been developed for use among Asian populations; and many analyses using stress inventories fail to differentiate the consequences of various sources of acculturative stress such as discrimination, family conflict, language skills, or legal status.

The current evidence does clearly indicate a link between racial discrimination and health. Youth who experience or perceive discrimination report more anxiety, more depressive symptoms, more risky health behaviors, lower self-esteem, and reduced academic motivations and expectations. ${ }^{20}$ Moreover, researchers have begun to link racial discrimination to a variety of physical health outcomes in minority children, including elevated blood pressure, elevated levels of glucocortisol hormones in the blood stream, and insulin resistance-conditions associated with high rates of coronary heart disease and inflammatory disorders. ${ }^{21}$

Evidence also shows a strong link between immigrants' family environments and health. On the one hand, familism-the strong family ties, trust, loyalty, and spirit of mutual support cultivated by many immigrant parents - and family responsibilities such as language brokering for adult parents can positively influence youths' emotional wellbeing. ${ }^{22}$ On the other hand, family conflict, parent-child acculturation gaps, and numerous family obligations can add to the stress experienced by children of immigrants and compromise their well-being. ${ }^{23}$

Much of the acculturation literature uses first- and second-generation immigrants' preferences for reading, writing, and interacting with friends in English rather than a foreign language as a primary measure of acculturation. These studies find that linguistically more acculturated youth have poorer health and engage in more risky health behaviors. In contrast, researchers know less about how age of migration, legal status, and the institutional and social contexts of reception influence children's health.

Children who immigrate at younger ages have greater language acquisition and better educational outcomes than children who immigrate at older ages, especially after puberty. However, their health risk profiles are more similar to children born in the United States to foreign-born parents. These young migrants find themselves caught between two worlds - the cultures of their parents and the cultures of their new communities. As they struggle to adapt, they tend to adopt more risky health behaviors such as alcohol use, smoking, and early sexual activity than their peers who immigrate at older 
ages. ${ }^{24}$ In addition, they face a higher risk of psychiatric disorders such as depression. ${ }^{25}$

Living in a liminal state between countries and without legal status can create daily hassles and become a source of chronic stress for children and their parents. A recent study of U.S.-born and foreign-born children of immigrants (from birth to age eighteen) whose parents had been arrested, detained, or deported during workplace raids by immigration officers sheds some light on the health consequences of legal status. ${ }^{26}$ It found that children in these families experienced feelings of abandonment, fear, social isolation, and anger. Moreover, family friends and teachers noticed changes in these children's behaviors immediately after the raids.

Finally, the influence of each of these stressors may vary by an immigrant's state of residence. Several researchers have begun to evaluate the link between how well immigrants are received in an institutional and social context and health outcomes. ${ }^{27}$ Historically, immigrants settled in six traditional gateway states-California, Florida, Illinois, New Jersey, New York, and Texas. Since 1990 immigrants have begun settling in new destination states across the Midwest (such as Indiana, Iowa, and Nebraska) and the South (such as Georgia, North Carolina, and Tennessee). These new destination states lack many of the institutional resources and multilingual professionals who help new immigrants settle and navigate complex U.S. health systems. Immigrants settling in these states also have smaller co-ethnic networks on whom they can rely for assistance and who can reinforce positive cultural norms and health behaviors for their children. Consequently, these immigrants have less access to health care and can be at greater risk of worsening health with time in the United States. ${ }^{28}$

\section{Promoting Physical Well-Being in Immigrant Children}

Pre-migration, migration, and post-migration stressors have the potential to harm the well-being of children of immigrants. Yet for a number of health indicators, foreign-born children experience better outcomes than do children in U.S.-born families. Foreignborn immigrant children typically have lower mortality and morbidity risks than both U.S.born children of immigrants and U.S.-born children of natives within their same racialethnic group; ${ }^{29}$ they have fewer specific acute and chronic health problems; and they have a lower prevalence of accidents and injuries than U.S.-born children. ${ }^{30}$

Over time and across generations, however, the health advantage of immigrant children fades. In this section, we summarize prevalence data on two key physical health indicators-obesity and asthma. These are two leading childhood health conditions in the United States with increasing prevalence among children of immigrants and long-term consequences for adult well-being. Because of the paucity of research on European and African children of immigrants, this summary focuses on Asian and Hispanic populations. To the extent that data are available, we highlight differences across immigrant generation and country of origin. In general, much of the research on Asian populations focuses either on Southeast Asians such as Vietnamese and Cambodians, Chinese, or Filipinos. Research on Hispanics focuses on Mexicans and Puerto Ricans.

\section{Overweight and Obesity}

Over the past three decades, the prevalence of excessive weight among children (aged six to nineteen) has increased from 5-7 percent to $17-18$ percent. ${ }^{31}$ Likely to become overweight adults, overweight children are at 
Figure 1. Prevalence of Overweight and Obesity among Children, by Ethnicity or Race and Immigrant Generation

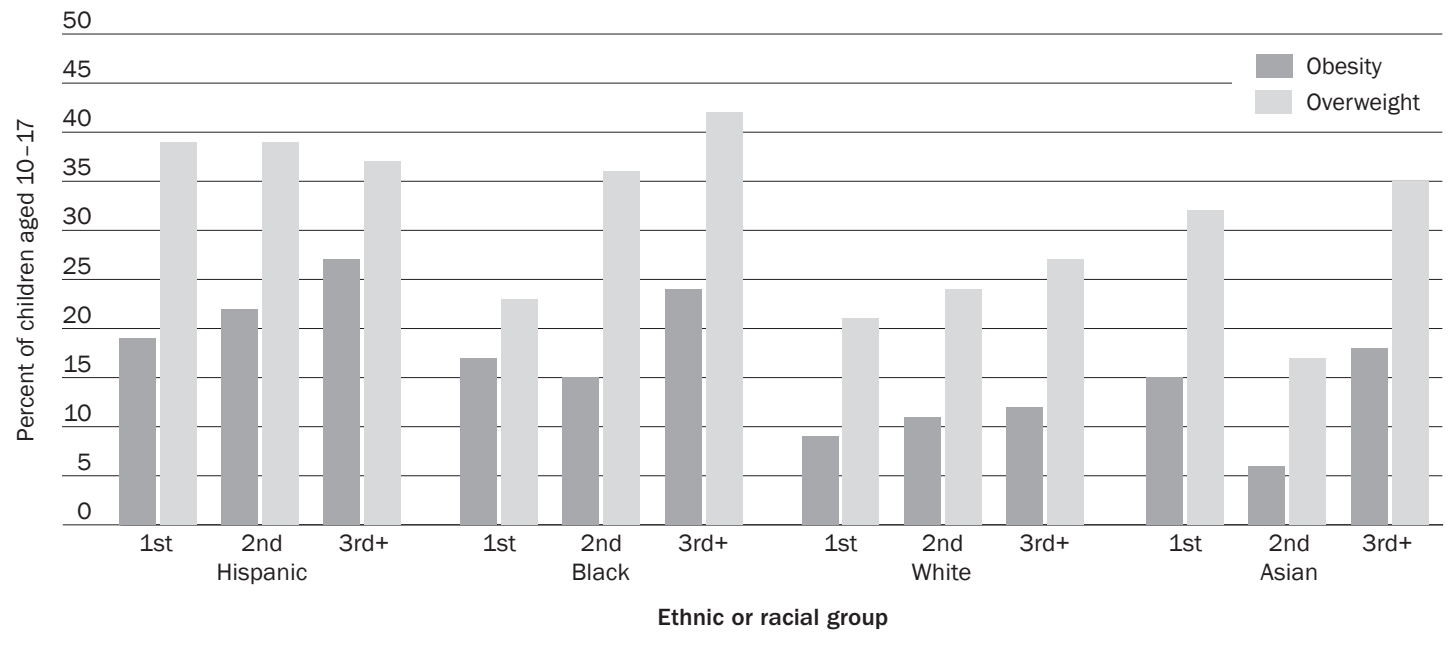

Source: Adapted from data in Gopal K. Singh, Michael D. Kogan, and Stella M. Yu, "Disparities in Obesity and Overweight Prevalence among U.S. Immigrant Children and Adolescents by Generational Status," Journal of Community Health 34, no. 4 (2009): 271-81.

increased risk of developing serious health conditions, including diabetes and cardiovascular disease.

Studies comparing foreign-born and U.S.born adolescents (aged twelve to twenty-six) have found that the share of adolescents who are overweight or obese is lowest for foreignborn youth, but these shares grow larger for each generation and increase rapidly as youth transition into adulthood. ${ }^{32}$ Among children aged ten to seventeen whose parents or grandparents are immigrants, Hispanics are most at risk of being overweight or obese, whereas non-Hispanic whites and Asians are the least at risk. Among all youth, thirdgeneration blacks have the highest rates of excessive weight (figure 1). ${ }^{33}$ These findings parallel those identified in studies of younger children (aged five to ten). ${ }^{34}$ As with adolescents, second-generation Hispanic boys are at greater risk of being overweight or obese than second-generation children of any other racial or ethnic background.
Diet significantly contributes to excessive weight among children and adolescents. As immigrants become more acculturated to U.S. society, they adopt American diets, which typically include greater amounts of fat, processed meats, snack foods, and fast foods than the diets in their countries of origin. ${ }^{35}$ Although these changes in dietary intake among immigrant adults are well documented, studies among youth are more limited. ${ }^{36}$ One study using the National Longitudinal Study of Adolescent Health (also known as Add Health) found that foreign-born Hispanic youth aged twelve to eighteen had generally healthier diets than Hispanic youth born in the United States. ${ }^{37}$ A second study using the 2001 California Health Interview Survey found that Asian and Latino foreign-born youth aged twelve to seventeen drank fewer sodas and ate more fruits and vegetables than non-Hispanic white U.S.-born children. ${ }^{38}$ But Latinos' fruit and vegetable consumption decreased and their soda consumption increased over time, 
while Asians' fruit, vegetable, and soda consumption stayed constant. Thus Asian children tended to maintain a lower risk of being overweight or obese than Latino children.

Low levels of physical activity further contribute to overweight and obesity among children. Rates of physical inactivity are high among foreign-born children. ${ }^{39}$ Eighteen percent of foreign-born immigrant children aged six to seventeen do not get any vigorous exercise in a typical week, and 56 percent do not take part in any team sports or games. By comparison 11 percent of U.S.-born children with U.S.-born parents do not exercise regularly, and 41 percent do not participate in organized sports. Compared with foreign-born Asian children, Hispanic foreign-born children had triple the rates of physical inactivity $(22.5$ percent to 7.4 percent); two-thirds of the Hispanic children did not participate in sports, compared with slightly more than one-third of the Asian children (66.6 percent to 37.6 percent). Asian children's higher rates of physical activity may also contribute to their reduced risk of obesity. Immigrant families may not be fully aware of the physical and mental health benefits of physical activity, may place a higher value on family or school activities, or may discourage participation in physical activities and sports. Most importantly, the structure of their daily lives (such as parents' work schedules) and their living conditions (neighborhood environments and access to recreational facilities, for example) may limit immigrant children's ability to engage in physical activities. ${ }^{40}$

\section{Asthma}

In 2008, nearly one of every ten U.S. children up to age seventeen had asthma, a leading chronic childhood disease, and rates of asthma are increasing worldwide. Patterns of asthma prevalence vary considerably by racial and ethnic group, with Asians having the lowest prevalence (4 percent), followed by Hispanics ( 7 percent), whites ( 9 percent), and blacks (16 percent). ${ }^{41}$

Although few studies have disaggregated the prevalence of asthma by country of origin or nativity, evidence suggests that across all racial and ethnic groups the children of immigrants have a lower lifetime prevalence of asthma than native children. ${ }^{42}$ Among Hispanic groups, Puerto Rican children have one of the highest rates of childhood asthma (19.2 percent in 2007), whereas Mexican children, whether immigrant or not, have one of the lowest rates (6.0 percent in 2008). ${ }^{43}$ Prevalence rates among Asian children aged two to seventeen vary from 4 percent for Asian Indians, to 5 percent for Chinese, to 11 percent for Filipinos. ${ }^{44}$

Because a diagnosis of asthma requires a visit to a health care provider, and because immigrants have less access to the health care system than nonimmigrants, rates among these groups may be underreported. Moreover, barriers to accessing health care can contribute to higher rates of hospitalization for asthma and poor asthma management among Hispanic children, immigrants, and other minority groups. ${ }^{45}$ In a recent study of Hispanic children aged five to twelve in New York City, asthmatic children from Spanishspeaking families were less likely to have an asthma diagnosis than children from Englishspeaking families but were twice as likely to be hospitalized for asthma (9.4 percent to. 4.4 percent). ${ }^{46}$ Another study of families in California found that asthmatic children of immigrants aged one to eleven were more likely to lack a usual source of care, report a delay in medical care, and report fair or poor health status than asthmatic children in nonimmigrant families. ${ }^{47}$ 
Figure 2. Prevalence of Substance Abuse and Mental Health Problems among Latinos, by Immigrant Generation

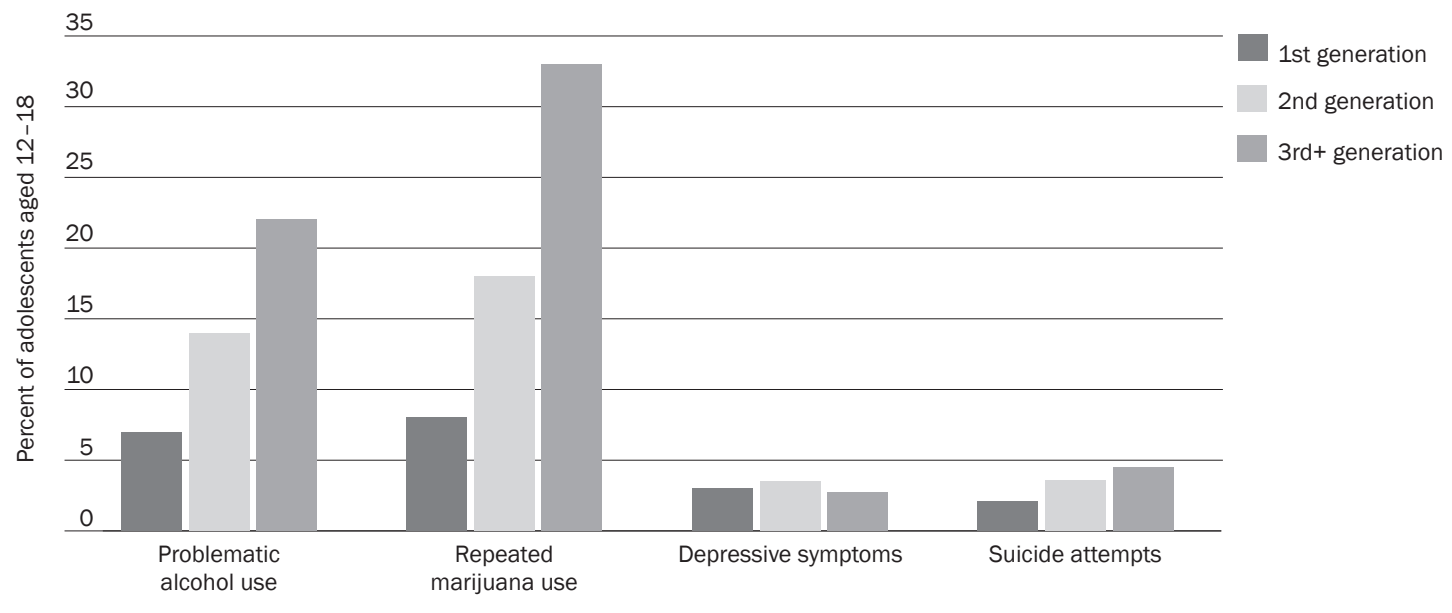

Source: Adapted from data in Juan Peña and others, "Immigration Generation Status and Its Association with Suicide Attempts, Substance Use, and Depressive Symptoms among Latino Adolescents in the USA," Prevention Science 9, no. 4 (2008): $299-310$.

\section{Protecting Emotional Well-Being in Immigrant Children}

While first- and second-generation children fare well on many aspects of physical wellbeing, this advantage relative to their native peers does not always translate into good mental health. Immigrant families experience a number of stressors that can affect the psychological well-being of all family members. These stressors affect children's emotional well-being, both directly and indirectly, by hindering parents' capacities to nurture their children's socioemotional development. ${ }^{48}$ As examples of how immigration influences children's emotional well-being, we look specifically at patterns of substance use, internalizing behavioral problems such as anxiety and depression, and externalizing behavioral problems such as hyperactivity, aggression, and conduct disorders. According to the U.S. Surgeon General's most recent report on mental health, these are the most common mental health concerns for children and adolescents. ${ }^{49}$

\section{Substance Use}

When they first arrive in the United States, children tend to participate in fewer risky health behaviors than those born in the United States. ${ }^{50}$ However, risky behaviors among foreign-born children increase with time spent in the country, especially during adolescence. Among these behaviors, patterns of substance use are particularly well documented among foreign-born adolescents aged twelve to seventeen. According to data from the 1999 and 2000 National Household Survey on Drug Abuse (NHSDA), rates of substance use (including cigarette, alcohol, marijuana, and other illicit drug use) were lower among foreign-born adolescents (9 percent for cigarettes, 12 percent for alcohol, and 4 percent for marijuana), in particular those who had been in the United States less than five years, than among U.S.-born adolescents ( 15 percent for cigarettes, 17 percent for alcohol, and 8 percent for marijuana). ${ }^{51}$ Prevalence estimates for foreign-born adolescents in the United States for ten or more years were not significantly 
different from estimates for U.S.-born youths, with one exception. U.S.-born youth had higher rates of heavy alcohol use than foreign-born adolescents.

Several studies examining substance use among Latino adolescents aged twelve to eighteen in Add Health found that secondgeneration youth were more likely to smoke cigarettes and use alcohol and marijuana than first-generation youth (figure 2). ${ }^{52}$ U.S.-born Hispanic youth were more likely than foreign-born Hispanic youth to report associating with substance-using peers, and peer substance use was directly associated with increased substance use. ${ }^{53}$

Few studies have assessed the impact of acculturation on the substance use of Asian children of immigrants. Asian American adolescents tend to have lower rates of smoking, alcohol, and drug use than other racial and ethnic groups. However, despite low rates overall, there are major differences by Asian ethnic group. Pacific Islander adolescents have higher rates of substance use, including alcohol, marijuana, and illicit drug use, compared with youth of other Asian ethnic groups.$^{54}$ One smaller study of Asian first- and second-generation adolescents aged fourteen and fifteen showed increases in substance use with length of time in the United States and interactions with substance-using peers. ${ }^{55}$

\section{Depression and Suicide}

Although no psychiatric epidemiological studies of children in the United States have been conducted, smaller communitybased studies and studies of symptom-level psychopathology indicate that anxiety and depression are the most prevalent conditions affecting the emotional well-being of children. ${ }^{56}$ In any given year, approximately 13 percent of children aged nine to seventeen experience symptoms of anxiety and 10-15 percent experience symptoms of depression. In addition, the vast majority of children and adolescents who commit suicide have experienced either anxiety or depression.

Although not conclusive, current research suggests that exposure to culture-related stressors and acculturation to the U.S. mainstream increases the risk of anxiety and depression among children of immigrants. In contrast, adherence to heritage cultures, a sense of belonging to their ethnic groups, and a number of family influences protect the children of immigrants from developing symptoms of anxiety and depression. Thus, mainstream integration may be problematic only when it is not coupled with the retention of one's cultural heritage, ethnic identity, and family strengths. ${ }^{57}$ For example, one study of Chinese immigrant families found that twelve- to fifteen-year-olds whose levels of acculturation were different from their fathers were more likely to report depressive symptoms. ${ }^{58}$ But another study of Chinese immigrant families found that a strong sense of family, measured by family obligations, was associated with decreased depressive symptoms among thirteen- to seventeen-yearolds. ${ }^{59}$ Similarly, data from Add Health suggest that social support from family, friends, and neighbors attenuates the risk of depressive symptoms and enhances the likelihood of positive well-being for all first- and second-generation adolescents aged twelve to eighteen. ${ }^{60}$ Parental closeness and the absence of parent-child conflict reduce the risk of poor mental health outcomes for second- and third-generation adolescents.

At its most extreme, poor mental health can lead to suicidal ideation and suicide among children of immigrants. Suicide is 
Figure 3. Health Insurance Coverage, by Citizenship and Length of Time in the Country

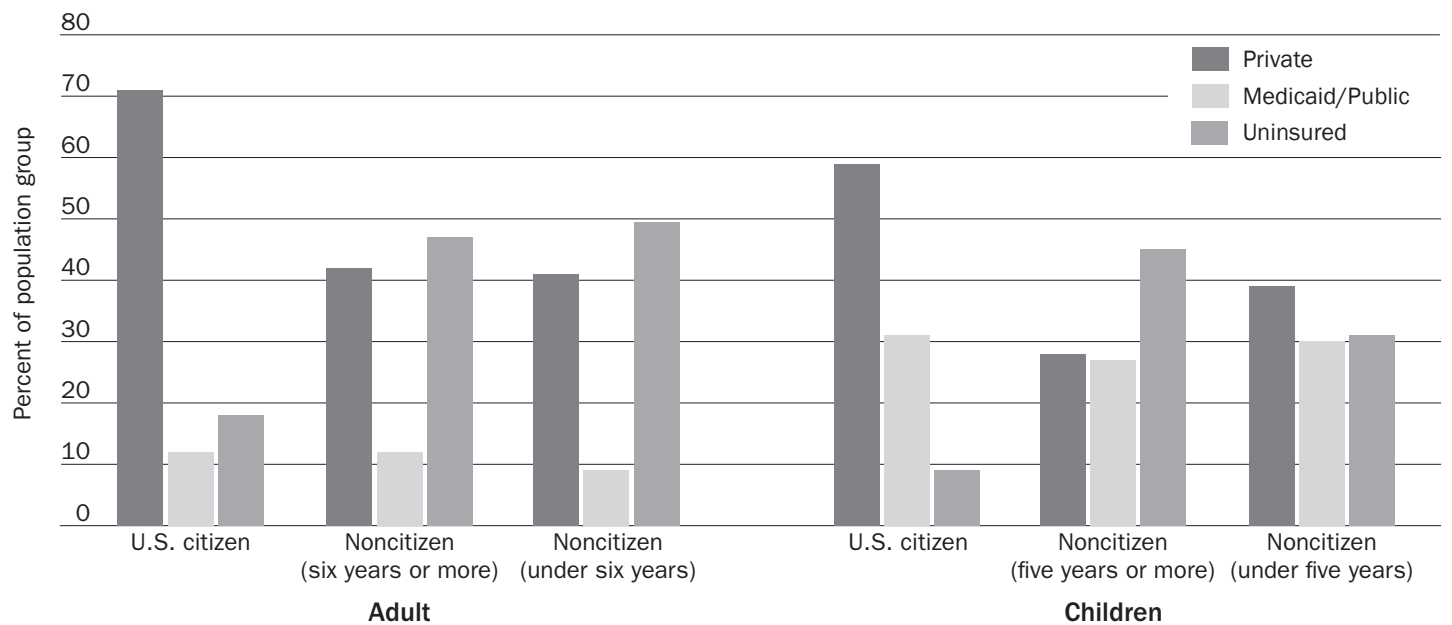

Source: Adapted from data in Kaiser Commission on Medicaid and the Uninsured, "Health Insurance Coverage in America, 2008" (Washington: Henry J. Kaiser Family Foundation, 2009).

the third-leading cause of death among all fifteen to twenty-four-year-olds. Although the 2007 Youth Risk Behavior Survey (YRBS) does not contain information on immigrant generation or acculturation, its data indicate that Hispanic students were as likely to have seriously considered suicide in the past year as other racial and ethnic groups but that more Hispanic youth reported making a suicide plan. ${ }^{61}$ Hispanic youth (both boys and girls) were also more likely to have attempted suicide (10 percent) than non-Hispanic white (5.6 percent) or black (7.7 percent) youth. A study using YRBS data from 1991 to 1997 found that Asian and Pacific Islander youth were less likely than Hispanics and more likely than either non-Hispanic white or nonHispanic black students to have made at least one suicide attempt. ${ }^{62}$

Those studies with specific data on immigrant generation or acculturation have found that acculturative stress is positively associated with suicidal ideation among Latino youth. ${ }^{63}$ In addition, the risk of attempted suicide among Latino adolescents doubles between the first and second generations (see figure 2). Research among Asian immigrant youth is much more limited, but results support acculturative stress theory. Under conditions of high parental-child conflict, less acculturated Asian adolescents report higher levels of suicidal behavior than do more acculturated youth. ${ }^{64}$

\section{Attention-Deficit/Hyperactivity Disorder}

Whereas internalizing behavioral problems such as depression tend to be most prevalent among females, externalizing symptoms associated with hyperactivity and conduct disorders are most prevalent among males. ${ }^{65}$ Furthermore, rates of attention-deficit/ hyperactivity disorder (ADHD) and conduct disorders are increasing among children and adolescents in the United States.

Although no national studies have assessed patterns of ADHD and conduct disorder 
among immigrant families, the prevalence varies significantly by racial and ethnic group. Data from the 2008 National Health Interview Survey showed that among three- to seventeen-year-olds, Hispanics were roughly half as likely as non-Hispanic whites or blacks to have been diagnosed with ADHD ${ }^{66}$ Only Asians reported fewer cases of ADHD than Hispanics, but the data are too imprecise to report. Once again, however, ethnic differences in diagnosed cases may reflect access to regular sources of medical care rather than true differences in prevalence rates. Even after receiving a diagnosis, both Hispanic and Asian children (aged three to eighteen) receive fewer medical care services than non-Hispanic whites. ${ }^{67}$

\section{Improving Access to Health Insurance and Health Care}

Access to health care substantially influences the physical and emotional health status of children of immigrants. Less likely to have health insurance and regular access to health care services, immigrant parents delay or forgo needed care for their children. When children finally receive care, it is often in the emergency room after an urgent or lifethreatening condition has developed.

\section{Health Insurance}

In 2008, nearly 45 percent of noncitizen U.S. residents, 18 percent of naturalized citizens, and 13 percent of U.S.-born citizens lacked health insurance coverage. ${ }^{68}$ Because most children depend on their parents to obtain health insurance, parental citizenship and immigration status can influence children's health insurance status (figure 3). Foreignborn parents and their children are more likely to be uninsured because parents are frequently self-employed or working for employers who do not offer health insurance, have lower incomes limiting their capacity to purchase insurance in the private market, and face restrictions on eligibility for public insurance programs. ${ }^{69}$ When offered insurance coverage by their employers, roughly 85 percent of employees take up this coverage, and there are no differences in take-up rates between citizens and noncitizens.

Immigrants' eligibility for public health insurance is dependent on federal and state policies. Coverage rates among legal immigrants have declined over the past decade as a result of 1996 welfare reforms that prohibited foreign-born children from receiving federally funded Medicaid and state Children's Health Insurance Program (CHIP) coverage until they had been in the country for at least five years. To fill this coverage gap, some states provided public insurance coverage using state-only funds. In the interest of promoting the health of newborns, several of these states also provided prenatal coverage to immigrant women regardless of their immigration status. In early 2009 the federal Children's Health Insurance Program Reauthorization Act updated the funding rules for CHIP and provided federal matching funds to states that covered eligible legal first-generation immigrant children and pregnant women regardless of their date of entry into the United States. However, states are not required to provide access to CHIP and can choose not to take advantage of the new option. As of February 2010, thirty states and the District of Columbia had chosen to provide public health insurance coverage to at least some qualified legal immigrants (figure 4). ${ }^{70} \mathrm{In}$ these thirty states, nearly one of every five children is a child of an immigrant.

Still, many children of immigrants (56 percent of children with two immigrant parents and 66 percent of children with one foreignborn and one U.S-born parent) eligible 
Figure 4. Medicaid or Children's Health Insurance Program Coverage of Pregnant Women and Children and Share of Children in Immigrant Families, by State

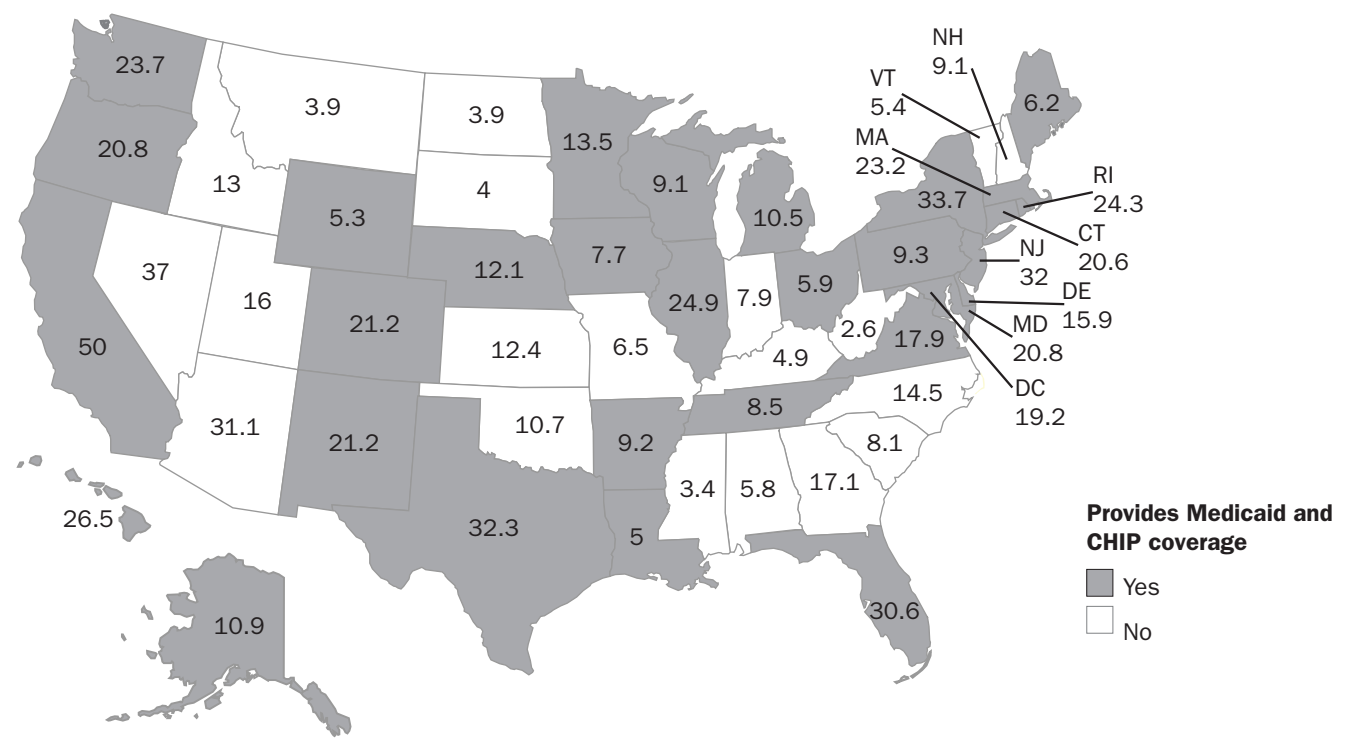

Source: Adapted from data compiled in National Immigration Law Center, Medical Assistance Programs for Immigrants in Various States (www.nilc.org/pubs/guideupdates/med-services-for-imms-in-states-2010-02-24.pdf); authors' calculations using U.S. Bureau of the Census, 2006-08 American Community Survey three-year estimates.

for public health insurance do not enroll. ${ }^{71}$ Approximately 81 percent of children (up to age eighteen) in immigrant families were born in the United States and are U.S. citizens. But an estimated 30 percent of children of immigrants are unauthorized or living with a parent who may not be living in the United States legally. ${ }^{72}$ Thus, parents of U.S. citizen children may forgo public health insurance and other services because of their own legal status and mistaken fears that they will be deemed a "public charge" if their children receive public health insurance benefits. ${ }^{73}$ Immigrants deemed a public charge can be denied U.S. citizenship or prohibited from sponsoring the immigration of a family member. In addition to concerns regarding their legal status, immigrant parents face financial and language barriers that can limit their capacity to enroll in both private and public health insurance programs.

\section{Health Care Use}

Without health insurance and even with insurance, families sometimes forgo critical preventive, diagnostic, and treatment services for their children. Among noncitizen children up to age seventeen, 37 percent lacked a usual source of care and 30 percent had not seen a medical doctor in the past year. Only 5 percent of citizen children lacked a usual source of care; only 9 percent had forgone an annual doctor's visit. Because they use less care, annual medical expenditures per capita were substantially lower for noncitizen children and their parents $(\$ 1,797)$ than for citizens $(\$ 3,702)$ in $2005 .{ }^{74}$

Both financial and nonfinancial barriers compromise the ability of immigrant parents to obtain access to medical care. ${ }^{75}$ Financial impediments include not only out-of-pocket costs for services and prescriptions but 
also the lack of paid sick leave or the ability to leave work to take their children to appointments during standard office hours. Language is one particularly important nonfinancial barrier for the children of immigrants and their parents. Immigrants with limited English proficiency report lower satisfaction with care, less knowledge of their medical condition, and difficulty understanding instructions on medication usage. Additionally, low levels of health literacy limit immigrant parents' abilities to use health services effectively or to act as advocates for their children in health care settings.

When immigrants face challenges obtaining physician-based medical care, they may turn to complementary and alternative medical providers such as acupuncturists or spiritual healers. Data from the California Health Interview Survey show that more than 22 percent of Latino and 23 percent of Asian adults reported using alternative medicine providers, and almost 20 percent of Latinos and 50 percent of Asians reported using traditional or herbal remedies. ${ }^{76}$

In addition, uninsured immigrants turn to health care providers working in federally qualified community health centers (FQHCs)_public and private nonprofit organizations serving populations with limited access to care. ${ }^{77}$ In 2008 FQHCs provided care to 17 million patients. Of these, 25 percent primarily spoke a language other than English, 36 percent were children, and 38 percent were uninsured. ${ }^{78}$ Uninsured immigrants, however, are less likely to use emergency rooms. Only 13 percent of adult and 12 percent of child noncitizens report an emergency room visit in the past year compared with 20 percent of adult and 22 percent of child citizens. ${ }^{79}$ Despite this lower frequency of use, emergency room expenditures are three times higher per capita for foreign-born children than for U.S.-born children. ${ }^{80}$ Thus, at least for children, delaying medical care can have substantial costs. Moreover, because immigrant parents cannot build long-term relationships with providers in these settings, their children may receive lower-quality care.

\section{Strategies to Promote Health}

To better promote the health of immigrant children, health researchers and reformers must improve their understanding of these children's unique experiences, reduce barriers to medical insurance for immigrant populations, and improve access to care and the capacity of providers to work with multilingual and multicultural populations.

\section{Understanding the Unique Experiences of Immigrant Children}

In the past decade, scholars have learned much about the immigrant experience and its influence on children's health. Still, critical knowledge gaps remain. As research progresses, scholars need to develop country-of-origin-specific, longitudinal, and binational data - data collected both in immigrants' countries of origin and in the United States_on immigrant parents and their children.

In the absence of data specific to country of origin, researchers classify immigrants into large pan-ethnic groups such as Asian and Hispanic. These groupings obscure substantial socioeconomic, cultural, and political differences that exist between the immigrant children from different countries of origin within the same world region and can lead to erroneous conclusions regarding the relationship between migration and health. 
To better understand the developmental consequences of migration, national longitudinal data on the children of immigrants are also sorely needed. Most data are gathered in specific geographic regions of the United States, are cross-sectional, and do not contain detailed information on both immigrant parents and their children. Consequently, researchers know little about how migration and acculturation experiences shape the development of children over time and across family generations. Moreover, the data do not allow researchers to identify how the context of settlement into particular areas of the United States shapes the health and development of immigrant children. States and communities vary widely in their cost of living, employment opportunities, racial composition, and infrastructure for serving immigrant families — all factors that can influence the health and development of children of immigrants.

Finally, comparable binational data are needed on the health of children and their parents. We cannot fully understand how migration and acculturation influence health without knowing more about the health of the populations from which immigrant children come and the context of their migration to the United States. Binational data will enable evaluations of how health, beliefs and attitudes about health, and health care use patterns in primary sending regions differ from those of the children of immigrants living in the United States. These data are critical for understanding health selection effects and designing effective prevention and treatment programs for an increasingly transnational population.

\section{Reducing Barriers to Medical Insurance}

Once immigrant parents and their children are in the United States, their health depends critically on their access to care- - a factor influenced substantially by insurance coverage. Four-fifths of the nation's 46 million uninsured are U.S. citizens. The Congressional Budget Office estimates that health care reform will, by 2019, reduce the number of uninsured to 23 million, one-third of whom will be nonelderly, unauthorized immigrants. ${ }^{81}$ Thus, health reform has important implications for access to medical care for immigrants and their children.

With the passage of the 2009 Children's Health Insurance Program Reauthorization Act, states now have the option of providing legal immigrant children and pregnant women access to federally funded health insurance through CHIP regardless of how long they have lived in the United States.

\section{Investments in health and health care are essential to the economic well-being of future generations of Americans.}

The policy for adults remains more restrictive. The health insurance reform bill passed in 2010, formally known as the Patient Protection and Affordable Care Act, bars legal immigrants from receiving Medicaid during their first five years in the country. However, immigrants who earn up to 400 percent of the federal poverty level and have no access to employer-provided coverage may purchase federally subsidized insurance through state exchanges. The new law makes unauthorized immigrant children and adults 
ineligible for Medicaid coverage and insurance options available through the exchanges. Medicaid will continue to cover only emergency care services for uninsured, unauthorized immigrants.

Despite the continued restrictions on adult immigrants' access to Medicaid, expansions in the availability of employer-provided coverage and in the eligibility of Medicaid will likely improve access to care. Employers with more than fifty employees will now be required to offer coverage to their workers, including immigrants and, potentially, their children. Additionally, single adults without children and with incomes up to 133 percent of the federal poverty line will now be eligible for Medicaid. Previous Medicaid eligibility requirements substantially limited coverage for adults without children. Finally, insurers will be required to cover children with preexisting medical conditions, and children can stay on their parents' insurance until age twenty-six. These are substantial improvements that will benefit millions of Americans, including immigrants.

\section{Improving Access to Medical Services}

On average, immigrants use less medical care, including less emergency room care, and have lower average medical expenditures than U.S. citizens. Health reform will begin to improve immigrants' access to care by relaxing restrictions on eligibility for public insurance and by improving affordability for individuals purchasing insurance through the nongroup market. However, additional steps will be needed to further promote access to care for the children of immigrants.

First, health care providers need to be sensitive to immigrants' cultures and their preferences for particular modes of delivery (that is, times, locations, and language). The availability of culturally competent care that respects patients' religious, family, and cultural values can improve the doctor-patient relationship and make it easier for immigrant parents to seek care. For example, because some immigrant populations rely on family, social networks, and complementary and alternative medicine for information about health and medical services, medical care providers can improve access to care by establishing lay health adviser programs designed to educate natural leaders in immigrant communities and build liaisons with these communities. Because immigrants can have limited access to a car and may not have a driver's license, providers can improve access by locating clinics within immigrant communities or near public transportation. And because immigrant parents may not have sick leave or flexible work schedules, clinic hours that extend beyond the standard 9-5 schedule can be essential to improving access. These and other possible strategies go beyond addressing the financial and linguistic barriers to medical care for immigrants.

Second, policy makers need to reduce additional structural barriers limiting the ability of immigrant children and their parents to access care. For example, federal civil rights policies require publicly funded providers to ensure that non-English speakers are able to access all their services, including applications and telephone appointment services. However, many states have not strictly enforced these requirements. Although Medicaid and CHIP allow states to include foreign-language interpreter services as an option, only twelve states currently do so. To encourage states to expand their translation and interpretation services, the health reform law has increased federal Medicaid and CHIP matching funds for these services. 
In addition, policy makers can also remove state and local ordinances requiring a patient to show proof of citizenship before receiving care provided by local public health departments and community clinics. These policies reduce access to care not only for immigrants but also for many citizens who lack proper forms of documentation such as birth certificates and passports.

Finally, states will need to invest in outreach to increase enrollment in health insurance programs and use of existing services.

Studies have shown that outreach efforts can ensure that immigrants take advantage of available services and use them efficiently. ${ }^{82}$ Without outreach efforts, immigrants may fail to take advantage of expansions in health insurance coverage and may remain unaware of improvements in other aspects of care (such as the availability of translators) available to them.

\section{Conclusion}

Poor health in childhood clearly can result in serious consequences for health, education, and employment in adulthood. Investments in health and health care are therefore essential to the economic well-being of future generations of Americans. Even though most foreign-born children arrive in the United States in good health, this health advantage dissipates over time as factors associated with migration and acculturation take hold. Low rates of health insurance and poor access to health care compound the risk for deteriorating health. Recent health reforms are a step in the right direction. To further promote the health of future generations of immigrant children, researchers and policy makers will need to better understand their unique experiences and continue to improve programs and policies that promote their access to medical services. 


\section{Endnotes}

1. Christian Gregory and Christopher Ruhm, "Where Does the Wage Penalty Bite?" (Boston: National Bureau of Economic Research, 2009); Alexander Cowell, Zhehui Luo, and Yuta Masuda, "Psychiatric Disorders and the Labor Market: An Analysis by Disorder Profiles," Journal of Mental Health Policy and Economics 12, no. 1 (2009): 3-17; Jeremy Bray, "Alcohol Use, Human Capital, and Wages," Journal of Labor Economics 23, no. 2 (2005): 279-312; Jeffrey DeSimone, "Illegal Drug Use and Employment," Journal of Labor Economics 20 (2002): 952-77.

2. Pinka Chatterji, "Illicit Drug Use and Educational Attainment," Health Economics 15, no. 5 (2006): 489 511; Francesco Renna, "The Economic Cost of Teen Drinking: Late Graduation and Lowered Earnings," Health Economics 16, no. 4 (2007): 407-19; V. Joseph Hotz, Susan McElroy, and Seth Sanders, "Teenage Childbearing and Its Life Cycle Consequences: Exploiting a Natural Experiment," Journal of Human Resources 40, no. 3 (2005): 683-715.

3. Anne Case, Angela Fertig, and Christina Paxson, "The Lasting Impact of Childhood Health and Circumstance," Journal of Health Economics 24 (2005): 365-89.

4. Janet Currie, "Health Disparities and Gaps in School Readiness," Future of Children 15, no. 1 (2005): 117-38; Robert Crosnoe, "Health and Education of Children from Racial/Ethnic Minority and Immigrant Families," Journal of Health and Social Behavior 47 (2006): 77-93.

5. Jason M. Fletcher, “Adolescent Depression: Diagnosis, Treatment, and Educational Attainment,” Health Economics 17, no. 11 (2008): 1215-35.

6. Joe Sean, Joe Emanique, and Larry L. Rowley, "Consequences of Physical Health and Mental Illness Risks for Academic Achievement in Grades K-12,” Review of Research in Education 33 (2009): 283-309; Janet Currie and Mark Stabile, "Mental Health in Childhood and Human Capital," in The Problems of Disadvantaged Youth: An Economic Perspective, edited by Jonathan Gruber (Boston: National Bureau of Economic Research, 2007).

7. Janet Currie and Mark Stabile, "Socioeconomic Status and Child Health: Why Is the Relationship Stronger for Older Children," American Economic Review 93, no. 5 (2003): 1813-23; James Smith, "The Impact of Childhood Health on Adult Labor Market Outcomes," Review of Economics and Statistics 91, no. 3 (2009): 478-89.

8. Alberto C. Palloni and others, "Early Childhood Health, Reproduction of Economic Inequalities and the Persistence of Health and Mortality Differentials," Social Science and Medicine 68, no. 9 (2009): $1574-82$.

9. Cynthia García-Coll and others, "An Integrative Model for the Study of Developmental Competencies in Minority Children," Child Development 67 (1996): 1891-914.

10. Linda Ko and Krista Perreira, “It Turned My World Upside Down: Latino Youth’s Perspectives on Immigration," Journal of Adolescent Research 25, no. 3 (2010): 465-93. Carlos Sluzki, "Migration and Family Conflict," Family Process 18 no. 4 (1979): 379-90.

11. Jennifer Van Hook and Kelly Balistreri, "Immigration Generation, Socioeconomic Status, and Economic Development of Countries of Origin: A Longitudinal Study of Body Mass Index among Children,” Social Science and Medicine 65 (2007): 976-89. 
12. Carola Suárez-Orozco, Irena Todorova, and Josephine Louie, "Making Up for Lost Time: The Experience of Separation and Reunification among Immigrant Families," Family Process 41 (2002): 625-43.

13. Jody Heymann and others, "The Impact of Migration on the Well-Being of Transnational Families: New Data from Sending Communities in Mexico," Community, Work and Family 12, no. 1 (2009): 91-103.

14. U.S. Department of Homeland Security, Office of Immigration Statistics. Yearbook of Immigration Statistics: 2009 (2010).

15. Stuart Lustig and others, "Review of Child and Adolescent Refugee Mental Health," Journal of the American Academy of Child and Adolescent Psychiatry 43, no. 1 (2004): 24-36.

16. Nancy S. Landale, Kevin J. A. Thomas, and Jennifer Van Hook, "The Living Arrangements of Children of Immigrants," in this volume.

17. Alberto Palloni and Jeffrey Morenoff, "Interpreting the Paradoxical in the Hispanic Paradox," Annals of the New York Academy of Sciences 954: 140-74; Luis N. Rubalcava and others, "The Healthy Migrant Effect: New Findings from the Mexican Family Life Survey," American Journal of Public Health 98, no. 1 (2008): $78-84$.

18. Sonia Nozario, Enrique’s Journey (New York: Random House, 2007).

19. Stephanie Potochnick and Krista Perreira, "Depression and Anxiety among First-Generation Immigrant Latino Youth: Key Correlates and Implications for Future Research," Journal of Nervous and Mental Disease 198, no. 7 (2010): 470-77.

20. Nancy Gonzales, Fairlee Fabrett, and George Knight, "Acculturation, Enculturation, and the Psychological Adaptation of Latino Youth," in Handbook of U.S. Latino Psychology, edited by Francisco A. Villarruel and others (Thousand Oaks, Calif.: Sage Publications, 2009).

21. Kathy Sanders-Phillips and others, "Social Inequality and Racial Discrimination: Risk Factors for Health Disparities in Children of Color," Pediatrics 124 (2009): S176-86.

22. Julia Love and Raymond Buriel, "Language Brokering, Autonomy, Parent-Child Bonding, Biculturalism, and Depression," Hispanic Journal of Behavioral Sciences 29, no. 4 (2007): 472-91.

23. Gonzales, Fabrett, and Knight, "Acculturation, Enculturation, and the Psychological Adaptation of Latino Youth" (see note 20).

24. Rachel Tolbert Kimbro, "Acculturation in Context: Gender, Age at Migration, Neighborhood Ethnicity, and Health Behaviors," Social Science Quarterly 90, no. 5 (2009): 1145-66.

25. Kathryn Harker, "Immigrant Generation, Assimilation, and Adolescent Psychological Well-Being," Social Forces 79 (2000): 57-65.

26. Ajay Chaundry and others, Facing Our Future: Children in the Aftermath of Immigration Enforcement (Washington: Urban Institute, 2010).

27. Alejandro Portes, Donald Light, and Patricia Fernández-Kelly, "The U.S. Health System and Immigration: An Institutional Interpretation," Sociological Forum 24, no. 3 (2009): 487-514; Kimbro, "Acculturation in Context: Gender, Age at Migration, Neighborhood Ethnicity, and Health Behaviors” (see note 24).

28. Peter Cunningham and others, Health Coverage and Access to Care for Hispanics in "New Growth Communities" and "Major Hispanic Centers" (Washington: Henry J. Kaiser Family Foundation, 2006). 
29. Robert Hummer and others, "Paradox Found (Again): Infant Mortality among the Mexican-Origin Population in the United States," Demography 22, no. 3 (2007): 441-57; Gopal Singh and Stella Yu, "Trends and Differentials in Adolescent and Young Adult Mortality in the United States, 1950 through 1993," American Journal of Public Health 86, no. 4 (1996): 560-64.

30. Namratha Kandula, Margaret Kersey, and Nicole Lurie, "Assuring the Health of Immigrants: What the Leading Health Indicators Tell Us,” Annual Review of Public Health 25 (2004): 357-76.

31. National Center for Health Statistics, Health, United States, 2008 with Chartbook on Trends in the Health of Americans (Hyattsville, Md.: U.S. Department of Health and Human Services, 2009).

32. Kathleen M. Harris, Krista M. Perreira, and Dohoon Lee, "Obesity in the Transition to Adulthood: Predictions across Race/Ethnicity, Immigrant Generation, and Sex," Archives of Pediatric and Adolescent Medicine 163, no. 11 (2009): 1022-28.

33. Gopal K. Singh, Michael D. Kogan, and Stella M. Yu, "Disparities in Obesity and Overweight Prevalence among U.S. Immigrant Children and Adolescents by Generational Status," Journal of Community Health 34, no. 4 (2009): 271-81.

34. Van Hook and Balistreri, "Immigrant Generation, Socioeconomic Status, and Economic Development of Countries of Origin” (see note 11).

35. Penny Gordon-Larsen and others, "Acculturation and Overweight-Related Behaviors among Hispanic Immigrants to the U.S.: The National Longitudinal Study of Adolescent Health," Social Science and Medicine 57, no. 11 (2003): 2023-34; Jennifer Unger and others, "Acculturation, Physical Activity, and Fast-Food Consumption among Asian-American and Hispanic Adolescents," Journal of Community Health 29, no. 6 (2004): 467-81.

36. Guadalupe Ayala, Barbara Baquero, and Susan Klinger, "A Systematic Review of the Relationship between Acculturation and Diet among Latinos in the United States: Implications for Future Research," Journal of the American Dietetic Association 108, no. 8 (2008): 1330-44.

37. Gordon-Larsen and others, "Acculturation and Overweight-Related Behaviors among Hispanic Immigrants to the U.S." (see note 35).

38. Michele Allen and others, "Adolescent Participation in Preventive Health Behaviors, Physical Activity, and Nutrition: Differences across Immigrant Generations for Asians and Latinos Compared with Whites," American Journal of Public Health 97, no. 2 (2007): 337-43.

39. Gopal K. Singh and others, "High Levels of Physical Inactivity and Sedentary Behaviors among U.S. Immigrant Children and Adolescents," Archives of Pediatrics and Adolescent Medicine 162, no. 8 (2008): 756-63; Unger and others, "Acculturation, Physical Activity, and Fast-Food Consumption among AsianAmerican and Hispanic Adolescents” (see note 35).

40. Katie Booth, Megan Pinkston, and Walker Poston, "Obesity and the Built Environment," Journal of the American Dietetic Association 105, no. 5, Supplement 1 (2005): 110-17.

41. Matthew Masoli and others, "The Global Burden of Asthma: Executive Summary of the GINA Dissemination Committee Report," Allergy 59, no. 5 (2004): 469-78; National Center for Health Statistics; U.S. Department of Health and Human Services, Summary Health Statistics for U.S. Children: National Health Interview Survey, 2008 (Hyattsville, Md.: 2009). 
42. S. V. Subramanian and others, "Contribution of Race/Ethnicity and Country of Origin to Variations in Lifetime Reported Asthma: Evidence for a Nativity Advantage.” American Journal of Public Health 99 (2009): 690-97.

43. Lara J. Akinbami and others, "Status of Childhood Asthma in the United States, 1980-2007," Pediatrics 123, Supplement (2009): S131-45.

44. Susan Brim and others, "Asthma Prevalence among U.S. Children in Underrepresented Minority Populations: American Indian/Alaska Native, Chinese, Filipino, and Asian Indian,” Pediatrics 122, no. 1 (2008): e217.

45. Deirdre Crocker and others, "Racial and Ethnic Disparities in Asthma Medication Usage and Health-Care Utilization: Data from the National Asthma Survey,” Chest 136, no. 4 (2009): 1063-71.

46. Luz Claudio and Jeanette Stingone, "Primary Household Language and Asthma Care among Latino Children," Journal of Health Care of the Poor and Underserved 20, no. 3 (2009): 766-79.

47. Joyce Javier, Paul Wise, and Fernando Mendoza, "The Relationship of Immigrant Status with Access, Utilization, and Health Status for Children with Asthma," Ambulatory Pediatrics 7, no. 6 (2007): 421-30.

48. Stephen Petterson and Alison Albers, "Effects of Poverty and Maternal Depression on Early Child Development," Child Development 72, no. 6 (2001): 1794-813; Elizabeth T. Gershoff and others, "Income Is Not Enough: Incorporating Material Hardship into Models of Income Associations with Parenting and Child Development," Child Development 78, no. 1 (2007): 70-95.

49. U.S. Department of Health and Human Services. Mental Health: A Report of the Surgeon General (Rockville, Md.: 1999).

50. Andrew Fuligni and Christina Hardway, "Preparing Diverse Adolescents for the Transition to Adulthood," Future of Children: Children of Immigrant Families 14, no. 2 (2004): 99-119; Kathleen M. Harris, "The Health Status and Risk Behaviors of Adolescents in Immigrant Families," in Children of Immigrants: Health, Adjustment, and Public Assistance, edited by Donald J. Hernandez (Washington: National Research Council and Institute of Medicine, 1999).

51. Joseph Gfroerer and Lucilla Tan, "Substance Use among Foreign-Born Youths in the United States: Does the Length of Residence Matter?” American Journal of Public Health 93, no. 11 (2003): 1892-95.

52. Jon Hussey and others, "Sexual Behavior and Drug Use among Asian and Latino Adolescents: Association with Immigrant Status," Journal of Immigrant and Minority Health 9, no. 2 (2007): 85-94; Juan Pena and others, "Immigration Generation Status and Its Association with Suicide Attempts, Substance Use, and Depressive Symptoms among Latino Adolescents in the USA," Prevention Science 9, no. 4 (2008): 299-310.

53. Guillermo Prado and others, "What Accounts for Differences in Substance Use among U.S.-Born and Immigrant Hispanic Adolescents: Results from a Longitudinal Prospective Cohort Study," Journal of Adolescent Health 45 (2009): 118-25.

54. Tracy Harachi and others, "Etiology and Prevention of Substance Use among Asian American Youth," Prevention Science 2, no. 1 (2001): 57-65.

55. Thao Le, Deborah Goebert, and Judy Wallen, "Acculturation Factors and Substance Use among Asian American Youth,” Journal of Primary Prevention 30, no. 3-4 (2009): 453-73. 
56. U.S. Department of Health and Human Services, Mental Health: A Report of the Surgeon General (see note 49); Glorisa Canino and Margarita Alegria, "Understanding Psychopathology among the Adult and Child Latino Populations from the United States and Puerto Rico," in U.S. Latino Psychology, edited by Francisco A. Villaruel and others (Los Angeles, Calif.: Sage Publications, 2009).

57. Gonzales, Fabrett, and Knight, "Acculturation, Enculturation, and the Psychological Adaptation of Latino Youth" (see note 20).

58. Su Kim and others, "Parent-Child Acculturation, Parenting, and Adolescent Depressive Symptoms in Chinese Immigrant Families," Journal of Family Psychology 23, no. 3 (2009): 423-37.

59. Linda Juang and Jeffrey Cookston, "A Longitudinal Study of Obligation and Depressive Symptoms among Chinese American Adolescents," Journal of Family Psychology 23, no. 3 (2009): 396-404.

60. Harker, "Immigrant Generation, Assimilation, and Adolescent Psychological Well-Being" (see note 25).

61. Centers for Disease Control and Prevention. Youth Risk Behavior Surveillance-United States, 2007. MMWR (Morbidity and Mortality Weekly Report) 57, No. SS-4 (2008): 1-13.

62. Jo Anne Grunbaum and others, "Prevalence of Health Risk Behaviors among Asian American/Pacific Islander High School Students," Journal of Adolescent Health 27, no. 5 (2000): 322-30.

63. Joseph Hovey, "Acculturative Stress, Depression, and Suicidal Ideation among Mexican-American Adolescents: Implications for the Development of Suicide Prevention Programs in Schools," Psychological Reports 83, no. 1 (1998): 249-50; Pena and others, "Immigration Generation Status and Its Association with Suicide Attempts, Substance Use, and Depressive Symptoms among Latino Adolescents in the USA" (see note 52).

64. Anna Lau and others, "Correlates of Suicidal Behaviors among Asian American Outpatient Youths," Cultural Diversity and Ethnic Minority Psychology 8, no. 3 (2002): 199-213; Noelle Yuen and others, "Cultural Identification and Attempted Suicide in Native Hawaiian Adolescents," Journal of the American Academy of Child and Adolescent Psychiatry 39, no. 3 (2000): 360-67.

65. Patricia Pastor and Cynthia Reuben, "Diagnosed Attention Deficit Hyperactivity Disorder and Learning Disability: United States 2004-2006," Vital Health Statistics 10, no. 237 (2008): 1-14; Carolyn ZahnWaxler, Elizabeth A. Shirtcliff, and Kristine Marceau, "Disorders of Childhood and Adolescence: Gender and Psychopathology," Annual Review of Clinical Psychology 4 (2008): 275-303.

66. National Center for Health Statistics, Summary Health Statistics for U.S. Children (see note 41).

67. Jack Stevens, Jeffrey Harman, and Kelly Kelleher, "Ethnic and Regional Differences in Primary Care Visits for Attention-Deficit Hyperactivity Disorder," Journal of Developmental and Behavioral Pediatrics 25, no. 5 (2004): 319-25.

68. Carmen DeNavas-Walt, Bernadette D. Proctor, and Jessica C. Smith, "Income, Poverty, and Health Insurance Coverage in the United States: 2008," Current Population Reports, P60-236 (U.S. Census Bureau, 2009).

69. Thomas Buchmueller and others, "How Did SCHIP Affect the Insurance Coverage of Immigrant Children?” The B.E. Journal of Economic Analysis and Policy 8, no. 2 (2008): 1-23; Thomas Buchmueller and others, "Immigrants and Employer-Sponsored Health Insurance," Health Services Research 42, no. 1P1 (2007): 286-310. 
70. Arkansas, Colorado, Florida, Louisiana, Michigan, Ohio, and Wyoming provide coverage to only a small number of lawfully residing pregnant women or children meeting certain additional eligiblity requirements or offer coverage for only a small number of services. National Immigration Law Center, Medical Assistance Programs for Immigrants in Various States (Los Angeles: 2010) (www.nilc.org/pubs/guideupdates/ med-services-for-imms-in-states-2010-02-24.pdf).

71. George Borjas, "Poverty and Program Participation among Immigrant Children," in this volume.

72. Jeffery Passel, "Demography of Immigrant Youth: Past, Present, and Future," in this volume.

73. Yoona Rhee, Frank Belmonte, and Saul Weiner, "An Urban School-Based Comparative Study of Experiences and Perceptions Differentiating Public Health Insurance Eligible Immigrant Families with and without Coverage for Their Children," Journal of Immigrant and Minority Health 11, no. 3 (2009): $222-28$.

74. Henry J. Kaiser Family Foundation, "Summary: Five Basic Facts on Immigrants and Their Health Care," (Washington: 2008).

75. Kathryn P. Derose, Jose J. Escarce, and Nicole Lurie, "Immigrants and Health Care: Sources of Vulnerability," Health Affairs 26, no. 5 (2007): 1258-68.

76. An-Fu Hsiao and others, "Variation in Complementary and Alternative Medicine (CAM) Use across Racial/ Ethnic Groups and the Development of Ethnic-Specific Measures of CAM Use," Journal of Alternative and Complementary Medicine 12, no. 3 (2006): 281-90.

77. T. Elizabeth Durden, "Usual Source of Health Care among Hispanic Children: The Implications of Immigration," Medical Care 45, no. 8 (2007): 753-60.

78. U.S. Department of Health and Human Services, 2008 Health Center Data (www.hrsa.gov/data-statistics/ health-center-data/NationalData/index.html).

79. Kaiser Family Foundation, "Summary: Five Basic Facts on Immigrants and Their Health Care" (see note 74).

80. Sarita A. Mohanty and others, "Health Care Expenditures of Immigrants in the United States: A Nationally Representative Analysis," American Journal of Public Health 95, no. 8 (2005): 1431-38.

81. Congressional Budget Office, Letter to Nancy Pelosi, Speaker of the United States House of Representatives, March 10, 2010.

82. Jennifer Kincheloe, Janice Frates, and E. Richard Brown, "Determinants of Children's Participation in California's Medicaid and SCHIP Programs," Health Services Research 42, no. 2 (2007): 847-66. 